University-Community Research Partnership 


\title{
University-Community Research Partnership for Community Empowerment in Tanzania
}

\author{
Rebecca G. Sima \\ Department of Educational Psychology, School of Education \\ University of Dar Es Salaam, Tanzania

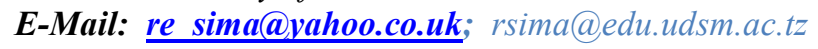

\begin{abstract}
This paper analyses the existing university-community partnership in research in Tanzania and proposes a bottom-top model instead of the traditional top-bottom approach which works with perceived needs of communities rather than real needs. Given their core missions, many universities assume that they achieve their missions, while communities do not appreciate universities' contributions for the advancement of both. As universities grow and increase in number, communities have remained poor. The proposal in this paper is for universities to plan and conduct research using the bottom-top model where community members can participate in explaining their problems which they need to be researched for solutions.
\end{abstract}

\section{INTRODUCTION}

Universities have a responsibility, among others, to improve the quality of life in their local communities. Functional and effective universities should be able to meet the needs of rapidly changing and increasingly complex societies through research partnerships. Many people are devastated by life's hardships while surrounded by enormous resources on which the university could work to help people exploit the resources to improve their lives. The first president of the Chicago University in the United States of America, William Rainey, described the mission of his University as "service for mankind whenever mankind is, whether within scholastic walls or without those walls and in the world at large" (Harkavy, 2000:9).

In many cases universities (in Africa / Tanzania) introduce, develop and offer programmes which are neither participatory nor democratic in nature, the situation which leads graduates to become roamers with no jobs because they did not have focus. Harkavy (2000 :) asserts that universities should rank among their high priorities, helping to create the local coalitions needed to establish, develop and maintain community-university partnership. Unless 


\section{University-Community Research Partnership}

universities learn from their history, think and foresee the future, the crisis in the communities will grow more severe.

To implement the university-community partnership work as intended is not an easy task particularly in poor countries such as Tanzania. In these countries there are too many priorities and perhaps no priorities at all (Please explain or clarify this statement). But the fact is that the universitycommunity partnership is feasible and could be one of the best approaches to reduce and ultimately eradicate poverty. My proposal is basically to optimally utilize the available resources to reach communities through research.

Community-university partnerships have gained momentum across the developed countries as a powerful force for revitalizing communities, fostering civic engagements and strengthening the core missions of higher education (Holland et al, 2003) in general and universities in particular. The cornerstone of community-university partnerships in those countries includes service-learning, community-based participatory research and partnerships focused on solving a particular problem or achieving a particular goal, such as economic development or workforce development among many other goals. The evidence base about these partnerships, factors contributing to their success and failure and their impact on participating researchers, communities and campuses, is growing. This is demonstrated by the increasing number of multi-site evaluation studies, peer-reviewed empirical journal articles, and meta-analyses in America - the United States of America? (Holland et al, 2003 :).

In Tanzania and perhaps in many other developing countries, this practice is far from reach (out of reach?). The challenge for our countries, therefore, is to derive some principles and best practices from the experienced countries to facilitate partnerships by translating created knowledge into practice and deal with policy issues, work on the knowledge gaps that exist between our countries and the developed world for future development. In practical terms, this challenge urges universities in Tanzania and other developing countries to strengthen the research component using the community-university partnership model for the purposes of quality improvement, knowledge advancement and partnership development to achieve the intended mission of relevance to the communities. The focus of this paper is on the mentioned challenge to universities in Tanzania. The partnership model in developing countries may need some modification to suit the contexts by involving community-based professionals in the partnership, instead of direct university-community partnership as applied in developed countries.

\section{The Rationale for the Partnership}

Universities lie at the heart of successful, leading economies around the world (Kent, 2006) and grow over time into large renowned research universities. The role of Tanzania's universities is not different from other 


\section{Rebecca G. Sima}

universities worldwide; rather the difference is in practice to fulfil the roles. It is a fact that universities deal with all matters occurring in the communities. In such circumstances, community development activities can use community based professionals such as teachers, lawyers, agricultural officers and other graduates from universities to communicate with universities to oversee 'social-contextual processes that are most powerful when collaboration and reciprocity are valued (Swick, 2001 in Edmore 2006: page number?). Therefore, collaboration in research between researchers from universities and community professionals as mediators on issues related to community development is inevitable in leading to communities' advancement and universities' growth.

The economic and social situations in Tanzanian communities indicate that there are a lot of economic and social problems requiring urgent attention by those with an interest in rural community development. There is a significant disparity between urban and rural in terms of poverty signified by the ability to meet basic human needs. Thus, universities in collaboration with rural based professionals can play a unique role in supporting the community plans on how to utilize the available resources for communities' development. In implementing this, the collaboration between professionals and universities is of great concern particularly in the context of the prevalence of income poverty.

It has been noted for example that, rural based teachers are prominent in community development activities such as literacy programmes (Edmore, 2006). Writers in the post 1980s, like Swanepoel (1985, 1987, 1996); Abbot (1995), Bryant and White (1984), Dore and Mars (1981), Gow and Vansant (1983), Makumbe (1996) and many others, have stated the importance of teachers' involvement in community activities but have not indicated how practically these teachers can take part in community development activities such as research or inclusion in community plans or both. Their focus on the rural poor and community development efforts does not specify the role professionals such as teachers can agricultural officers, health workers and lawyers who work in communities can play.

Edmore (2006) quoting McClenaghan (2000) points out that community development, among other purposes, involves citizens in collective activities aimed at socio-economic development. However, the involvement of community professionals is not shown as if they are not part of the citizenry community development. Literature on the collaboration between professionals, communities and universities is silent regarding the part these professionals can play to enhance the development of both the community and universities. Community based professionals live, work and always interact with the poor, yet their participation in research with universities has not been regarded. Therefore, there is a need to illuminate the role the professionals can play in collaboration with universities in doing research with the focus on the prevailing community problems for solutions. Given the context of abundant but less utilized resources in our communities, it is evident that there is lack of full utilization of available community 


\section{University-Community Research Partnership}

professionals by universities in researching, planning and implementing community development activities targeting at poverty alleviation in the country.

The current practice of community focused research activities in Tanzanian universities

Research activities in Tanzanian Universities follow a top-bottom mode. University staff/researchers write proposals focusing on general problems in the country and particularly the problems which are in the common agenda between the funders and the universities. The proposals attract funds to allow researchers conduct research in places of their choice. In this kind of practice, the community members are unaware until that time when researchers visit their places and ask for community consent to participate in generating data as informants but not necessarily beneficiaries of the research outcome. And in many cases they are treated as research guinea pigs (Baum, 2000) or research objects; they have no choice but to concur.

In a more meaningful but also unfulfilling, some researchers would do the same but with a focus on a particular project with particular funding opportunity, but with the same disregard of the deeper and broader goals and expectations of both the university and the community which are not brought to the table for discussion. In this case the community under research may benefit somehow in some aspects of the project, but even then the sustainability would always be unfulfilling and questionable. The best example of this approach is the NORAD projects at the University of Dar es Salaam (UDSM) whereby many projects have been done with communities; but as soon as the project period expires (normally two years) the communities relapse into their original state of poverty or any kind of problems they had experienced before the project. There are no sustainability plans and mechanisms for the projects. Researchers take advantage of poverty prevalence in the country to assume that communities are homogeneous without considering level of poverty and their priorities. The fact that priorities of communities are disregarded the researched community members remain silent about what researchers do and for whose benefit.

This is a major shortfall because the issues of ownership, relevance to the researched communities, and sustainability of the projects and growth of universities are questionable. These have resulted into continued underdeveloped communities in almost all rural parts of Tanzania while the universities themselves have not gained recognition as relevant to communities. Moreover, the approach suffers another limitation that some parts of the country are over-researched because they are the areas where most university researchers come from and/or perhaps have some characteristics that are demanded by funders. However, underdevelopment and poverty in rural Tanzania remain rampant as if nothing goes on as far as research is concerned. 


\section{Rebecca G. Sima}

This mode of operation can be categorized into what Martin and Etzkowitz (2000) refer to as mode 1, which involves new knowledge being produced primarily within individual disciplines in universities and other academic institutions. In this mode there is little direct connection to societal needs and the results of the research are transferred at the end of the project to users who may or may not take up those results. This kind of mode for university researchers defeats the universities' aspiration to grow into centres of excellence to win global competitiveness. It therefore calls for a more practical approach or mode 2 of Martin and Etzkowitz (2000) in which research knowledge is produced in the context of application, with societal needs having a direct influence from an early stage and with relatively explicit social accountability and responsibility.

In the context of our nation mode 2 can be achieved through community-university partnership in which community participation goes beyond being research informants as in the current practice or mode 1 . Universities should recognise and accept their responsibilities to their communities and act to fulfil them (Harkavy, 2000) which involves taking risks and as Clark (1998) puts it, that taking risk when initiating new practices whose outcome is in doubt becomes a major factor for working with communities. Autonomous universities become active institutions when they decide they must explore and experiment with changes in how they are composed and how they react to internal and external demands (Clark, 1998:5). Think of mushrooming universities today; should old universities still operate in the same way to compete with the newly developed small universities? Realistically, the old universities should move towards changing their many ways of operation including the way they operate in research activities. If they don't take initiative to change, then the younger universities can take that risk and in the final analysis may overturn the flagship universities which seem, as Clark (1998) puts it correctly, "to depend on their outstanding reputation and political clout" (pg 5). Senior university staff should be courageous enough to take risks because they have experience and they are influential.

\section{Challenges to Universities in Tanzania}

Universities in developed world have gone far from where our universities are, they have developed their societies and created knowledge societies. Our universities need to run to take their pace while universities in developed countries are walking. What have our universities done so far to develop communities in an effort to alleviate poverty and themselves gain reputation and aim towards growing into research universities? The long term challenge for Tanzania has been to overcome poverty which has continued to be a major constraint to socio-economic development. The Tanzanian Development Vision 2025 envisages to attain sustainable human development and to raise the living standards of people. The 2025 vision plans include attaining a high quality of livelihood, creating a strong 


\section{University-Community Research Partnership}

economy and putting in place firm foundations for good governance and rule of law. To achieve a high quality of livelihood, the Vision considers a nation with high quality of education at all levels, a nation which produces the quantity and quality of educated people sufficiently equipped with the requisite knowledge to solve the society's problems, to meet the challenges of development and attain competitiveness at regional and global levels (URT, 2000). This is a direct challenge to universities which are charged with creating knowledge to raise the living standard of the people in the country.

At independence when the first flagship university (The UDSM) was established, it was anticipated to become a strategic partner of the government in the fight against poverty among other challenges. Almost fifty years after independence this poverty is still the major challenge. Since agriculture has all along been the backbone of the country's economy, the government established another university, Sokoine University of Agriculture (SUA) focusing specifically on agriculture with the same thinking and belief that the agricultural based university would rescue the country from extreme poverty. Yet the situation remains almost the same considering traditional hand-hoe agriculture which does not contribute much in the fight against poverty.

The universities' graduates are supposed to be working with communities for the purpose of bringing about development in these communities to alleviate poverty. The major question then would be "what is it that was expected to be done; that universities in Tanzania are not doing? As it has always been correctly asked by many people "Higher Education for what? This is the situation in which Martin and Etzkowitz (2000) point out that some pessimists believe that the future of universities is under threat from governments and others who expect universities to do more useful things such as to produce more applied knowledge and to develop more useful skills into their students. If this does not happen, the trend is seen as potentially threatening the integrity of the universities along with their longcherished autonomy.

\section{University-community partnership for sustainable community development}

By partnering with communities, the universities may work to help improve economic, social and physical conditions of their communities, and also work with the legal rights on many controversial issues. White (1984), Huntington (1980), Coombs (1980) and Swanepoel (1989) in Edmore (2006) defend the need to use local expertise in communities since, without it, planning is flawed creating bottlenecks in communities' advancement. They argue that local people are the world's leading authorities in matters concerning their community, and should be offered an opportunity to give input into the social and political environment, as well as their traditions, values, psychological outlooks, lifestyle and the daily hardships they face. 


\section{Rebecca G. Sima}

A sustainable community is the one which uses its resources to meet current needs while ensuring that adequate resources are available for future generations. It seeks a better quality of life for all its residents while maintaining nature's ability to function over time by minimizing waste, preventing pollution, promoting efficiency and developing local resources to revitalize the local economy. Decision-making in a sustainable community stems from a rich civic life and shared information among community members. A sustainable community resembles a living system in which human, natural and economic elements are interdependent and draw strength from each other. The concept of a "sustainable community" does not describe just one type of neighbourhood, town, city or region. Activities that the environment can sustain and that the citizens want and can afford may be quite different from community to community. Rather than being a fixed thing, a sustainable community is continually adjusting to change while preserving the environment's ability to support it. ${ }^{1}$

Writers continue to argue that University-community partnership can work to achieve the following for the purpose of creating sustainable communities.

- $\quad$ Redesigned and improved infrastructure;

- $\quad$ Knowledge-based services;

- $\quad$ Environmental technologies;

- Improved management;

- Use of natural resources;

- $\quad$ Supportive government policies;

- $\quad$ Expanded training;

- $\quad$ Establishing use of information technologies for networking;

- $\quad$ Sustainable tourism activities centred around areas of cultural, and historic significance;

- $\quad$ Adding value to marine, agricultural and forest products; and

- Developing, manufacturing and marketing products, services and technologies that reduce environmental burdens.

Sustainability of the community will be enhanced by the triangular relationship between the community, the university and the professionals where feedback to universities by the professionals will serve as a breakthrough in communication continuity (see also Figure 1).

\section{The partnership model}

There is guarantee in Tanzania that the available universities are capable of producing professionals but the main challenge is proper utilisation in research of the professionals to bring about change in communities. The major role of the professionals if they were to develop communities and shape universities would be mediating university- community partnership. Important in this is the mutual working relationship between the 


\section{University-Community Research Partnership}

professionals and community members. The mutual relationship allows the professionals to discuss problems surrounding the community for solutions, then communicate the problems to universities to facilitate research activities to find solutions for the existing problems. The universities respond by taking initiatives to conduct research on the identified problems with the involvement of professionals and community members.

The approach towards solutions to community problems will enhance university-community partnership. Research universities should recognize and accept that they are responsible for the development of their communities and act faithfully to fulfil that mission. Currently universities produce professionals but there is no direct feedback from the community- based professionals on what happens in the communities and what their problems are for the University to research on for solutions.

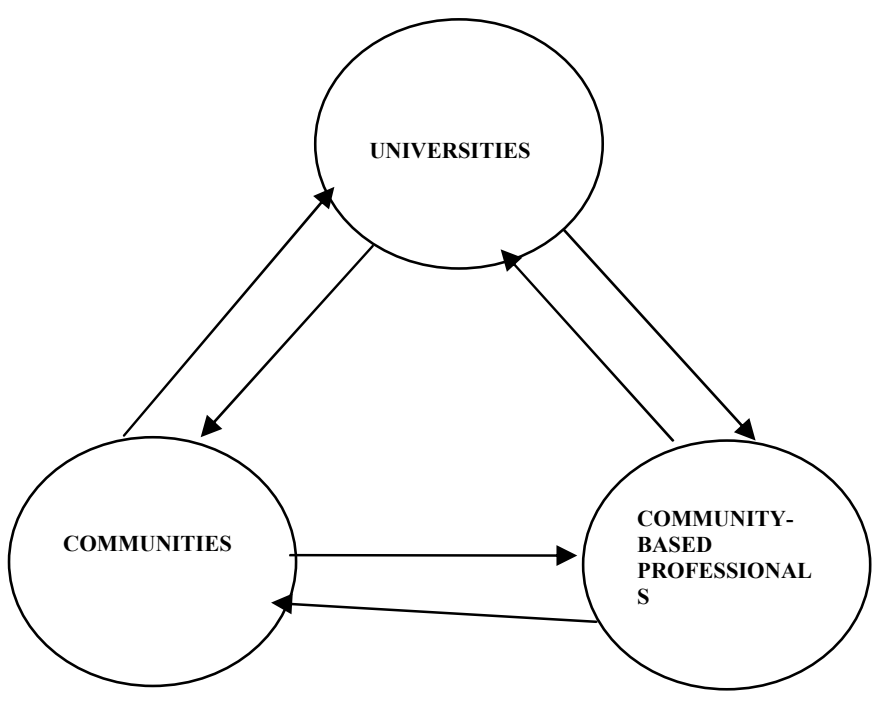

Fig. 1: The University-community partnership model mediated by professionals.

(Source: Adopted from Eckhoff (1967) with substantial modifications).

Interpretation of the model to explain how each of the three partners reciprocates the relationship (the six arrows in the model)

\section{How can universities relate to professionals?}

Universities produce professionals to help community members with different problems. However, professionals become not only community 
experts but also part of their respective communities socially, economically, politically and culturally which creates conducive atmosphere for productive cooperation.

\section{How can professionals relate to universities?}

The professionals can give feedback to universities on what is happening in communities including informing community problems to be researched on for provision of solutions. Successful professionals give value to their respective universities and their communities.

\section{How can the communities relate to the community professionals?}

Communities accept and appreciate the professionals as their experts. They make use of available professionals to solve their problems and improve their livelihood for development. More useful professionals in the community gain more acceptance and are utilized more hence become more powerful than the lesser useful professionals who lose popularity and power.

\section{How can community-based professionals relate to communities?}

Community -based professionals ought to share their knowledge with community members to bring about change in their respective communities.

\section{How can universities relate to communities?}

Universities create knowledge through research and the knowledge is used to change communities' livelihood through community-based professionals. Universities have the responsibility to disseminate knowledge to communities to create knowledge societies.

\section{How can communities relate to universities?}

Unless there is impact of university created knowledge to communities, the communities will not recognise the existence of universities or will declare that universities are useless institutions, or universities are for individual benefits because those who go to university get employment and earn money to live. Communities can influence policies if they benefit from universities. Rich communities may fund research activities. However, communities support research in many ways including participating in defining and clarifying the problems and suggesting solutions for the problems.

This kind of partnership has worked very well elsewhere such as in the United States of America (USA) for the development of communities which own universities with the intended goals as 


\section{University-Community Research Partnership}

- To continue to develop and improve on the positive relationship between the university and the community by focusing on honest dialogue about key issues facing the university and the community

- $\quad$ To create a venue to address concerns and develop positive interactions between the university and local professionals with emphasis on problems of local residents, and law enforcement agencies ${ }^{2}$

In our case where the university is not community based, then comes the importance of working with professionals who are community-based but representing the community on the one hand and the university on the other.

\section{Towards achieving university-community research partnership for sustainable communities: The role of universities}

Universities are the indispensable players in the advancement of scientific knowledge, which continuously seeds new generations of applied research, scientific breakthroughs and streams of new products that enhance our lives and strengthen our economy. Universities' innovations centre around three ingredients: knowledge creation, knowledge diffusion and knowledge application that form the core of the activities of today's leading research universities. Talented people create the knowledge; universities diffuse that knowledge into the society; and the communities often in collaboration with universities, take advantage of these ideas and bring them into practice (Rubin, 2000). Universities play a central and strategic role in educating and training the scientists, professionals, researchers, and other skilled workers. Universities, especially those which engage extensively in research, disseminate the knowledge and ideas by way of student education, faculty interactions, collaborations with community projects, and through a variety of other mechanisms such as trainings, workshops and seminars.

Partnerships that link universities with communities to address community problems through research can be mutually beneficial. Universities can conduct research and use the findings to practise in communities. Communities at the same time get help for understanding and improving their conditions (Baum, 2000). The partnership in research is a kind of an effective mechanism for community-directed research for development. Community-based or community directed research is defined as research that "is ... conducted by, for or with participation of community members" (Loka Institute, 2002 cited in Savan, 2004). Participation of community members can be by representation and in our case the professionals and other knowledgeable members can represent to collaborate with universities in stating and defining and clarifying the problem. The university researchers can make sense of the problem and guide the methodology, interpret the findings to provide solutions to the problems. The most important feature of community-based research partnered by University 


\section{Rebecca G. Sima}

is its inclusiveness of community members in carrying out the research activities and not to remain as research subjects. Community members do not want to be research guinea pigs and they do not want to wait for action, they want to act (Baum, 2000). As Loka Institute (2002) in Savan (2004) argues that the community based research aims at understanding of the problem and ensures that the knowledge gained contributes to making a concrete and constructive difference in the world. Hence the essence of the community participating and acting in research.

Community based research model has been developed to share with or devolve to community and other agencies the resources and sometimes the power in determining research goals and outcomes (Savan and Sider, 2003). It tries to marry community development with knowledge creation and since it is participatory in nature, it is premised on the notion that local communities ought to be full partners in the process of knowledge creation and social change (Flicker et al, 2008). Since knowledge creation is one of the basic activities of universities then collaborative research will be developing the community, while the university will also be creating new knowledge for the community's utilization in advancement and same knowledge be shared nationally and globally through publications. Global scholars have argued that collaborative research between community and university may be an important strategy to more effectively address disparities in many areas (Asley and Gaventa, 1997).

This is particularly most important in Tanzania where many forms of disparities such as rural-urban, gender, social status, political involvement, health and education to mention but a few are rampant. It is now time to increase collaboration across and between communities and universities as advocates of community based research suggest (Flicker et al, 2008). Hall (1993) gives it more flavour by writing that participatory research is fundamentally about to speak. It is a way which gives chance to researchers and the poverty stricken people in the poor world to join in solidarity to take collective long and short term actions for social change. The approach at the best interest of all parties attempts to break down the distinction between researchers and the researched (Gaventa, 1993) through the shared knowledge.

Both action research and participatory traditions place an emphasis on meaningful involvement of stakeholders in applied social research concerned with problem solving and social change. More important is that the applied social research focuses on building stronger partnerships between academics and communities (Flicker, 2008). By its nature, research activity is hierarchical in the sense that the researcher assumes power over the researched. Foucault (1980) argues that universities have long operated in a privileged space, with the power to shape and produce expert discourses, and at times this power has been abused to cause a kind of distrust. Further, Flicker et al (2008) contend that individual partnership teams no matter how well intentioned, still operate in socially and politically inequitable environments that privilege certain knowledge systems over others. 


\section{University-Community Research Partnership}

However, Hall (1993) points out that participatory practice validate people's knowledge and therefore there is a need to challenge power imbalances which rarely disappear. Flicker (2006) suggests one of the ways of challenging these pervasive hierarchies. That is to explicitly mention the imbalances, address them head-on and ensure that the benefits of the partnership are equitably distributed. Since research is a process within the partnership there is a need to work with these power differences right from the planning stage so as to avoid some resistance from the powerful (the researchers).

\section{How can university-community partnership be operationalised?}

Having observed some bottlenecks in university-community partnerships elsewhere, Baum (2000: 242-244) suggests some important features to be observed in research partnership. The features include the following:

\section{Clarify and specify realistic partnership purposes}

The partnership should aim at improving the university (in terms of research) and the community (in terms of sustainable development). Both parties need to be honest about what they can accomplish, considering the difficulties and establishing the ability to plan and conduct evaluation. Short of all these, dishonesty, cynicism and blame will inevitably follow.

\section{Match Resources to Purposes}

Resources should match partnerships' original purposes. Three kinds of resources matter in the partnership which involves an academic component. The first is knowledge especially if the partnership intends to design a programme to address a specific problem. In our case, here is where the professionals who work in communities become very important to help define the problem. For example, it will need a teacher to design a programme related to literacy issues and define the resources to match with the intended programme. Time, a second resource, is needed for learning how a partnership can be formed, what it should do, how it should be reformed to do that, and what else it might do. University and community partners may take time to develop sufficient understanding of and trust in one another as well as build confidence in shared knowledge, to act. University and community members must have enough time to see things happening, to see the course of action and assess the results. It is because knowledge and time are so important that money is the third crucial resource. In most cases this needs a third-party funding as rarely do universities commit funds for research, and communities can hardly handle the funding.

In this case the university administration must assume the responsibility to solicit funds from either the government or donor community as it is always the case. Clark (1998) suggests that universities should adopt the 


\section{Rebecca G. Sima}

diversified funding base to fashion this new change-oriented character because it generally requires greater financial resources: it particularly needs discretionary funds. Widening the financial base becomes essential, since virtually everywhere mainline institutional support from government, as a share of total budget, is on the wane. Enterprising universities recognise this trend and turn it to an advantage by putting more efforts to raise money from other sources including vigorously competing for grants and contracts, from the intellectual property, earned income from campus services, students' fees, and alumni fund raising. Universities need to get away with the dependency on a single support by trying to utilise as many opportunities as possible. Although many governments in developing countries claim that they are too poor to facilitate research activities but the issue of political will to make research a priority is also an issue of concern.

\section{Make funders partners}

In developed nations universities have vast networks of foundations which they can easily partner for financial support. In developing countries the major funder is the government and development partners/donor agencies through the government or other research authorities. The government or the donor agency can provide funds to facilitate the university and community research partnerships. In this case the government should join the partnership in the monitoring and evaluation stages to ensure that the intended partnership has been achieved to improve both the university and the community. The government and other funders in such a partnership will learn about and from what they are paying for better at firsthand rather than merely through written reports. They will develop stronger investment bond in their projects and a sense of responsibility for them, and they will have more constructive influence over their development (Baum, 2000: 243).

\section{Make partners accountable to one another}

Parties must commit themselves to do what they can do to establish a durable partnership (see figure 1) to figure out what its goals should be and what partners must do to reach them, and to secure resources needed to accomplish their purposes. They must be willing to contribute time, knowledge, relationship, authority and appropriate material resources. They must respond to one another's requests. Articulating these obligations between and among parties will often be difficult but it is central to successful research partnership.

\section{Organise continually}

Partnerships require continued organising. In many communities particularly the poorest, there is little formal organisation. People may have interest in issues but lack time, skills or confidence to take part in meetings. Community 


\section{University-Community Research Partnership}

members need information about issues and activities, encouragement and assistance to attend meetings, training and coaching and to be helped to analyse problems and develop responsive strategies if they are to participate in community life. Ongoing effort is necessary to nurture partners, get their attention, develop work groups, arrange productive meetings, plan and implement projects.

Baum (2000) merges all these issues into two main principles that can make partnerships work effectively. First and foremost is for university and community to think, agree explicitly, clearly and specifically about their shared purposes and what they must do to accomplish them. Secondly, is for the university and community to provide flexibility, time and resources necessary for them to learn, change their minds, change their identities and change their directions. At this juncture the university must take the lead with the help of the community professionals to help the community members understand what ought to be done for the advancement of both parties.

\section{Benefits/ Contribution of university-community research partnership for development:}

According to Savan and Sider (2003) and Savan (2004), the following are the benefits of university-community partnership can serve a variety of research, policy, educational and action goals Can enhance the capacity of community groups to engage in long-term advocacy on particular issues and redefine issues in their own terms and even more broadly as the understanding of issues gets higher.

If the partnership takes longer time it strengthens university-community links, raises university profile and enhances the image of the university while improving the credibility and capacity of the community, innovation in problem definition, research approach and outcome.

The long-term collaboration fosters the trust and shared values critical to successful work involving partners based in widely differing institutional settings.

Promotes progressive social change as well as deeper understanding of specific issues important to communities.

- Improves knowledge, problem solving and decision-making capacity of community organizations and university partners to provide insights into how sustainability practices work and how they can successfully combine economic development, environmental protection and social equity.

- Opportunities for undergraduate and graduate students to undertake unique research, training and work experiences that will inform and implement sustainability in a variety of settings. 


\section{Rebecca G. Sima}

- A framework for increased networking among universities and community organizations that are investing in initiatives for the promotion of sustainability in order to ensure enhanced alliancebuilding, mutual learning through complementary research and action agendas, and shared dissemination efforts.

Enhanced social and economic community development characterised by action and research initiatives that promote and achieve tangible gains for sustainability, long-lasting community-university linkages and increased opportunities for hands-on experience for university students and researchers as well as for non-governmental organisations.

Besides the mentioned benefits drawn from all over the world, others can be contextual. Universities can make a kind of strong commitment to link their curriculum and programmes that reflect the community needs to allow graduates to be absorbed directly in communities for service. This will serve not only employment purposes but also will help improve people's way of life and infrastructure to facilitate implementation of different projects. This kind of partnership can attract funds from within and outside the country. Funders can only fund more if they see tangible things happening in communities. Feedback from the communities through professionals will help the universities to evaluate themselves and grow.

\section{CONCLUSION}

University-community partnership in research has worked very well in some of the developed countries to develop communities and universities to grow and gain high recognition and credibility. The model has also worked very well to develop knowledge societies. In Tanzania mushrooming of universities is witnessed but relevance of all these universities to the surrounding communities is questionable. This paper has highlighted the university-community model which could be used by these universities to make them relevant to their communities. The model calls for universities to engage communities in identifying problems to be researched for solutions. The paper has proposed some modifications in the proposed model by proposing engagement of community professionals to be part in the practice so that the partnership can fit in our communities in which most of the members are not equipped with research tools but can be assisted by the professionals in their areas of expertise. In this way, newly established universities can compete with the long standing and flagship universities which otherwise could be difficult to compete. 


\section{REFERENCES}

Abbot, J. (1995). "Community Participation and its Relationship to Community Development" in Community Development Journal, 30(2): $36-54$

Asley, F. and Gaventa, J. (1997) "Researching for Democracy and Democratizing Research" in Change, Vol. 29 (1): 46-67.

Baum, H. (2000). "Fantasies and Realities in University-Community Partnerships" in Journal of Planning Education and Research, 20: 234-246.

Bryant, C. and White L. G. (1984). Managing Rural Development with Small Farmers Participation, Westhartford: Kumarian Press.

Clark, B. (1998) Creating Entrepreneurial Universities: Organizational Pathways of Transformation, Paris: Pergamon.

Dore, R. and Mars, Z. (1981) Community Development: Comparative Case Studies in India, The Republic of Korea, Mexico and Tanzania, London: Croom, Helm Publishers.

Eckhoff, T. (1967). Vitenskaper, profesjoner of klienter, Nordisk Forum.

Edmore, N. (2006) The Participation of Rural based Teachers in Community Development Activities in the Chivi District, Masvingo, Zimbabwe, Development Studies, South Africa

Flicker, S. (2006) "Who benefits from Community based Participatory Research?" in Health, Education and Behaviour, 12 (3): 120-136.

Flicker, S., B. Savan, B., McGrath, M., Kolenda, B. and Mildenberger, M. (2008) "If You Could Change One Thing, What Community based Researchers Wish They Could Have Done Differently" in Community Development Journal, 43(2): 239-253.

Foucault, M. (1980) Power/Knowledge: Selected Interviews and Other Writings, New York, NY: Pantheon.Gamble.

Gaventa, J. (1993) The Powerful, the Powerless and the Experts: Knowledge Struggles in an Information Age. In Voices of Change: Participatory Research in United States and Canada. Ed. Park, P. Brydon-Miller, M. Hall, B. and Jackson, T.. Toronto, Ontario: Institute for Studies in Education, 21-40.

Gow, D. D. and Vansant, J. (1983) "Beyond the Rhetoric of Rural Development Participation: How It Can Be Done?" in World Development, 11(5), 105-120.

Hall, B. (1993) Introduction. In Voices of Change: Participatory research in United States and Canada. Ed. Park, M. B.-M. P. Hall, B. \& Jackson, T. Toronto:OISE Press: 21-40.

Harkavy, I. (2000) School-Community-University Partnerships: Effectively Integrating Community Building and Education Reform, Joint Forum Betweeen the U.S Department of Education and the U.S Department of Housing and Urban Development, Washington, DC.

Holland, B. A., Gelmon, S. (2003) "Community-University Partnerships: What Do We Know?" in Community-University Partnerships: 
Translating Evidence into Action, San Diego: Community-Campus Partnership for Health: 1-19.

Kent, H. (2006) "University Research and Local Economic Development: A product of Arizona State University's Productivity and Prosperity Project (P3)", Arizona.

Makumbe, J. M. (1996) Participatory Development: The Case of Zimbabwe, Harare.

Martin, B. and Etzkowitz, H. (2000) "The origin and Evolution of the University Species" in Organisation of Mode 2/Triple Helix Knowledge Production, Goteborg University: SPRU: 1-25.

Rubin, V. (2000) "Evaluating University-Community Partnerships: An Examination of the Evolution of Questions and Approaches" in A Journal of Policy Development and Research, 5(1): 219-230.

Savan, B. (2004) "Community -University partinerships: Linking Research and Action for Sustainable Community Development" in Community Development Journal, 39 (4): 372-384.

Savan, B. and Sider, D. (2003) "Contrasting Approaches to Communitybased Research and a Case Study of Community Sustainability in Toronto, Canada" in Local Environment, 8(3): 303-316.

Swanepoel, H. J. (1985). "Community Development. Alive in our Memories or in Our Development Efforts?" in Development Southern Africa, 2(2).

Swanepoel, H. J. (1987). Copmmunity Development and Particaipation. In Kotze, D. A. De Beer, F. C. Swanepoel, H. J. and Bembridge, H. J. in Rural Development Administration in South Africa, Pretoria:African Institute of South Africa.

Swanepoel, H. J. (1996). "Evaluation of Community Development Project: A Human Development Approach." in Africanus, 26(1).

URT (2000) The Tanzania Development Vision 2025, Dar es Salaam: United Republic of Tanzania. 